\title{
Sociedade civil e regulação da mídia: estudo de caso sobre o PL da mídia democrática
}

\section{Alessandra Maia Terra de Faria, Theófilo Codeço Machado Rodrigues e Larissa Santiago Ormay}

\section{Resumo}

0 objetivo do presente artigo é refletir sobre a forma pela qual uma parcela da sociedade civil brasileira trouxe para a esfera pública 0 debate sobre a regulamentação dos artigos constitucionais que tratam da comunicação social. Para tanto, foi recortada enquanto estudo de caso a recente mobilização social em torno do projeto de lei de iniciativa popular da mídia democrática. Em um primeiro momento, são discutidos os artigos constitucionais relacionados ao tema da comunicação social e sua regulamentação, ou não regulamentação, nos últimos 27 anos. Ao analisar tais processos, é testada a hipótese que orienta este artigo, qual seja, a de que um projeto de lei de iniciativa popular pode se mostrar uma estratégia bem-sucedida para a sociedade civil ao tornar o tema - mídia - pauta da agenda nacional de democratização.

\section{Palavras-Chave}

Regulação da mídia. Sociedade civil. Esfera pública.

\section{Alessandra Maia Terra de Faria ।}

alessandramtf@gmail.com

Doutora pelo Programa de Pós-Graduação em Ciências Sociais da Pontifícia Universidade Católica do Rio de Janeiro e professora no Programa de Graduação e Especialização Lato Sensu da mesma Instituição.

\section{Theófilo Codeço Machado Rodrigues |}

theomachado@gmail.com

Realiza doutorando no Programa de Pós-Graduação em Ciências Sociais da Pontifícia Universidade Católica do Rio de Janeiro PUC-Rio, Brasil.

Larissa Santiago Ormay | Irssa7@gmail.com Realiza doutorado no Programa de Pós-Graduação em Ciência da Informação da Universidade Federal do Rio de Janeiro - UFRJ, Brasil.

\section{Introdução}

0 presente artigo busca recuperar e refletir sobre a forma como uma parcela da sociedade civil brasileira trouxe para o domínio da esfera pública nos últimos anos o debate acerca da regulamentação dos artigos constitucionais que tratam da comunicação social. Para tanto, foi recortada como estudo de caso a mobilização social em torno do projeto de lei de iniciativa popular da mídia democrática.

A literatura especializada vem apontando, há algum tempo, para o déficit regulatório existente para a atuação dos meios de comunicação no Brasil. Embora a Constituição de 1988 tenha em seu corpo um capítulo dedicado ao tema da comunicação social - artigos 220, 221, 222, 223 e 224 -, alguns desses dispositivos jamais foram regulamentados em lei, ou seja, passaram-se quase 30 anos sem que fossem aplicados plenamente.

0 argumento comum que permeia a literatura especializada para justificar esse déficit regulatório residiria no poder de lobby dos 
empresários da mídia no Congresso Nacional, seja na Câmara dos Deputados, seja no Senado Federal. Esse poder é exercido por uma grande bancada interna ao parlamento, mas também por uma enorme pressão externa desempenhada pela influência da imprensa sobre a agenda legislativa.

A partir da percepção da interdição do debate no âmbito do parlamento, uma parcela expressiva da sociedade civil brasileira, articulada em torno do Fórum Nacional pela Democratização da Comunicação (FNDC), girou seu foco de ação para pautar o tema na esfera pública. Partia-se do princípio de que o debate só obteria sucesso dentro do parlamento se viesse de fora como agenda prioritária da sociedade. Foi nesse sentido que, em 2013, o FNDC formulou um projeto de lei de iniciativa popular, cujo escopo busca a regulamentação dos artigos da Constituição que tratam do tema da comunicação social. Pela legislação brasileira, um projeto de lei de iniciativa popular (PLIP) precisa recolher assinaturas de pelo menos $1 \%$ da população eleitoral do país para que entre em tramitação no Congresso Nacional, ou seja, cerca de 1.300 .000 assinaturas. A estratégia política adotada pelo FNDC, portanto, foi a de utilizar o projeto de lei de iniciativa popular como instrumento de agitação, politização, mobilização e pressão sobre o parlamento em torno da agenda da regulação da mídia.
São quatro os principais itens que constam no projeto de lei de iniciativa popular da mídia democrática formulado pelo FNDC: (1) a regulamentação do artigo 220 da Constituição através da proibição da propriedade cruzada dos meios de comunicação; (2) a regulamentação do artigo 221 que trata da regionalização da produção cultural; (3) a criação do direito de antena para os movimentos sociais no sistema de rádio e televisão, sob forte inspiração da legislação portuguesa; (4) e 0 direito de resposta que se encontra em um vácuo legislativo desde 2009, quando o Supremo Tribunal Federal (STF) declarou inconstitucional a Lei de Imprensa. ${ }^{1}$

0 presente artigo está dividido em três seções. Em um primeiro momento (1), são apresentados os artigos constitucionais relacionados ao tema da comunicação social e a maneira como se deu sua regulamentação ou não regulamentação nos últimos 27 anos. Ou seja, trata-se do contexto histórico e político que informou a decisão de ser criado o projeto de lei de iniciativa popular da mídia democrática. Em seguida (2), são apresentados o conteúdo do projeto de lei de iniciativa popular e a estratégia adotada pela sociedade civil em geral, e pelo FNDC em particular, para levá-lo ao Congresso. Por fim (3), expomos a forma como o debate 
da regulação da mídia alcançou a esfera

pública nos últimos anos. Para tanto, reunimos, de um lado, alguns dos editoriais dos principais veículos da mídia impressa que abordaram o tema de modo contrário à proposta do FNDC. Do outro lado, as principais atividades e demais formas que os movimentos sociais encontraram para tentar recolher as assinaturas necessárias para 0 encaminhamento do projeto para a tramitação na Câmara dos Deputados. Aqui observamos, por exemplo, como a narrativa do PLIP passou a fazer parte do discurso da então presidenta Dilma Rousseff, bem como os então presidentes da Câmara dos Deputados e do Senado, Eduardo Cunha e Renan Calheiros, respectivamente, passaram a criticar a proposta.

Espera-se com esse trabalho testar a hipótese de que, ao analisar o conteúdo do projeto de lei de iniciativa popular cotejando-0 com as estratégias adotadas pela sociedade civil para levá-lo ao Congresso, é possível destacar como as últimas teriam sido bem-sucedidas no sentido de tornar o tema pauta da agenda nacional de democratização. Como resultado, 0 artigo visa apresentar não somente uma das formas de organização da sociedade civil que pauta 0 tema da democratização da mídia, a partir de suas táticas e estratégias organizativas, mas, também, salientar alguns dos elementos que tornam o marco legal das comunicações ainda insuficiente.

\section{0 contexto regulatório da comunicação}

Data de 1962 o Código Brasileiro de Telecomunicações, o qual regula até os dias de hoje as telecomunicações e a radiodifusão no Brasil. Embora, ao longo destes mais de 50 anos, muitas emendas tenham sido aprovadas para compatibilizá-lo com o desenvolvimento das novas tecnologias da informação, o fato é que sua concepção geral é, certamente, relativa a um tempo já ultrapassado não apenas pelas inovações tecnológicas, mas também pelas inovações sociais e democráticas. Uma primeira grande tentativa de atualização desse conjunto de regras que envolvem a radiodifusão no Brasil veio com a Constituição de 1988. Os cinco artigos destinados ao tema da comunicação social na Constituição orientam uma rigorosa regulamentação estatal sobre as empresas de comunicação. Nesses artigos, podemos observar diretrizes regulatórias claras, como é possível destacar de acordo com o exposto no quadro 1, sobre Diretrizes da Comunicação Social. Estaria dentro de tais diretrizes a proibição de que se constituam em objeto direto ou indireto de monopólio ou oligopólio; a regionalização da produção cultural, artística e jornalística; a proibição de capital estrangeiro nas empresas de comunicação; a possibilidade de complementariedade entre os sistemas público, estatal e privado e a própria existência de um Conselho Nacional de Comunicação Social. 
Quadro 1: Diretrizes da Comunicação Social

\begin{tabular}{|l|l|}
\hline Artigos & \multicolumn{1}{|c|}{ Diretrizes } \\
\hline Art.220 & $\begin{array}{l}\text { Os meios de comunicação social não podem, direta ou indiretamente, } \\
\text { ser objeto de monopólio ou oligopólio. }\end{array}$ \\
\hline Art. 221 & Regionalização da produção cultural, artística e jornalística. \\
\hline Art. 222 & Proibição de capital estrangeiro nas empresas de comunicação. \\
\hline Art. 223 & Complementariedade entre os sistemas público, estatal e privado. \\
\hline Art. 224 & Existência de um Conselho Nacional de Comunicação Social. \\
\hline
\end{tabular}

Fonte: Adaptado a partir de BRASIL, 1988. Elaboração nossa.

Além desses enumerados anteriormente, há ainda 0 artigo 21 da Constituição que garantia o monopólio estatal das telecomunicações. Ocorre que, enquanto alguns desses artigos não chegaram a ser regulamentados até os dias de hoje - caso do Art. 220, 221 e 223 -, ou seja, não se tornaram efetivos, outros foram modificados completamente em seu conteúdo original - é o exemplo dos Arts. 222 e 221. Dos três artigos que não foram regulamentados, apenas um deles, 0 Art. 221, chegou a ser debatido na esfera pública e no parlamento. 0 artigo 221 foi o único que chegou a entrar no debate público e tramitar no parlamento. De acordo com seu texto:

Art. 221 - A produção e a programação das emissoras de rádio e televisão atenderão aos seguintes princípios: I - preferência a finalidades educativas, artísticas, culturais e informativas; II promoção da cultura nacional e regional e estímulo à produção independente que objetive sua divulgação; III - regionalização da produção cultural, artística e jornalística, conforme percentuais estabelecidos em lei; IV - respeito aos valores éticos e sociais da pessoa e da família. (BRASIL, 1988)
A primeira tentativa de regulamentá-lo veio com o projeto de lei (PL) 256/1991, de autoria da deputada federal do Rio de Janeiro Jandira Feghali (PCdoB - Partido Comunista do Brasil). 0 projeto criava cotas de produção regional e independente nas grades de programação das emissoras de rádio e televisão. 0 PL foi apresentado em 12 de março de 1991, contudo passaram-se mais de 24 anos sem que fosse aprovado. Em 2003, chegou a ser aprovado na Câmara dos Deputados, mas, em meados do fim de 2014, foi, finalmente, arquivado no Senado. Os outros dois artigos que não foram regulamentados - Art. 220 e 223 - nem chegaram a ocupar espaço na esfera pública.

Aqui se sugere que é possível a alusão desse caso ao exemplo daquilo que Bachrach e Baratz (2011) definiram na teoria política como "não decisão". Conforme observado em Rodrigues (2014), na teoria política a "não decisão" não significa apenas que determinada medida não seja 
efetivada, mas sim que recursos políticos sejam mobilizados de modo que aquela determinada medida não entre sequer na agenda pública ou que tenha meios de ser aprovada.

Tal ocorreu de forma distinta dos artigos anteriores, tanto 0 Art. 222 quanto o Art. 21 foram, de fato, regulamentados. Essa regulação, todavia, aconteceu em relação aos mencionados dispositivos constitucionais no sentido de alterar por completo os seus conteúdos originais. Em um primeiro momento, a Emenda Constitucional (EC) $\mathrm{n}^{0} 08$, de 1995, modificou 0 artigo 21 da Constituição para acabar com o monopólio estatal das telecomunicações. A EC caminhava junto com as políticas gerais de privatização que tiveram espaço na década de 1990 no Brasil. Já a Emenda Constitucional $\mathrm{n}^{0}$ 36, de 2002, alterou o artigo 222 da Carta Magna para abrir a possibilidade de que até 30\% do capital das empresas de comunicação fosse estrangeiro. Em síntese: a Constituição de 1988 teve clara preocupação com a regulação das empresas de comunicação. Tal preocupação, no entanto, não coligiu para a efetivação de seus dispositivos, visto que foram reelaborados distanciando-se de seu sentido original. Alternativas para esse estágio atual da regulação são o tema da próxima seção.

\section{0 projeto de lei de iniciativa popular da mídia democrática}

Como vimos na seção anterior, já se passaram 26 anos sem que alguns dos principais artigos da
Constituição de 1988 que tratam da regulação dos meios de comunicação viessem a ser regulamentados. Tal inércia e/ou omissão do poder legislativo suscitou um grande conjunto de organizações da sociedade civil reunidas em torno do Fórum Nacional pela Democratização da Comunicação (FNDC) a buscar um caminho alternativo. Esse caminho alternativo foi a formulação de um projeto de lei de iniciativa popular (PLIP) como estratégia de pressão sobre o parlamento.

De acordo com 0 artigo 61 da Constituição de 1988, os eleitores brasileiros podem apresentar na Câmara dos Deputados um projeto de lei de iniciativa popular se ele tiver sido subscrito por, "no mínimo, um por cento do eleitorado nacional, distribuído pelo menos por cinco Estados, com não menos de três décimos por cento dos eleitores de cada um deles" (BRASIL, 1988). Isso significa, atualmente, a necessidade do recolhimento das assinaturas de aproximadamente 1 milhão e 300 mil eleitores para que um PLIP passe a tramitar na Câmara. Isso dificulta a mobilização social em torno das leis de iniciativa popular, ainda que um exemplo que logrou sucesso nesse sentido e foi atingido através de um PLIP que a Câmara dos Deputados aprovou em 2010 foi a lei que ficou conhecida como Ficha Limpa. Em 2015, a Câmara dos Deputados aprovou, de forma praticamente unânime, a Proposta de Emenda Constitucional que garante a redução das assinaturas necessárias em um PLIP para 500 mil; tal alteração, contudo, para ser aprovada como lei, ainda precisa passar pelo Senado. 
À época da Constituinte, por exemplo, as emendas populares foram propostas por eleitores maiores de 18 anos, com subscrição mínima de 30.000 eleitores, recolhidas por três associações civis ou determinadas entidades públicas, Assembleias Legislativas e Câmaras de Vereadores, inclusive, conforme apontado em Faria (2014). Cada eleitor poderia subscrever, no máximo, três propostas para a futura Constituição. No total, foram 12.277.423 assinaturas, o que implicou o envolvimento estimado de mais de 4 milhões de cidadãs e cidadãos. De acordo com estudos sobre o tema, as emendas populares potencializaram a inserção constituinte dos movimentos sociais organizados, cuja representação era minoritária entre os membros da Assembleia Nacional Constituinte.

Nesse sentido, a percepção do FNDC foi a de que a estratégia de busca das assinaturas para o PLIP teria duas vantagens: (1) a politização e mobilização social em torno do tema; (2) a visibilidade da ampla base popular que legitima a proposta, a fim de evitar seu imediato arquivamento na tramitação junto à Câmara dos Deputados. É possível destacar aqui, também, uma possível retomada de certa tradição democrática presente no Momento Constituinte (FARIA, 2014, p. 9798), mas que, no seu período posterior, tem sido pouco utilizada enquanto expediente estratégico pela sociedade civil organizada. 0 pontapé inicial para essa estratégia foi a XVI Plenária do FNDC, realizada em 9 e 10 de dezembro de 2011, e que aprovou um Plano de Ação tendo como eixo central um novo Marco Regulatório das Comunicações.

Esse Plano de Ação convocou o "Seminário Desafios da Liberdade de Expressão", realizado no dia 4 de maio de 2012, no Sindicato dos Engenheiros de São Paulo, para apontar os elementos fundamentais que deveriam constar nesse marco regulatório. 0 Seminário contou com cerca de 200 participantes, representando aproximadamente 100 entidades nacionais e 20 estados de todo o país. Em 27 de agosto de 2012, data de aniversário dos 50 anos do Código Brasileiro de Telecomunicações, foi lançada em todo o Brasil a campanha nacional "Para expressar a liberdade!", com o objetivo de divulgar na sociedade a necessidade de um novo marco regulatório para as comunicações. A campanha estava na rua, mas ainda não tinha um PLIP como instrumento concreto de mobilização. Até que, em 14 de dezembro de 2012, uma plenária nacional da campanha "Para expressar a liberdade!" criou um Grupo de Trabalho formado por pesquisadores e representantes da sociedade civil, voltado para a formulação do conteúdo do PLIP. ${ }^{2}$ Entre os dias 14 de dezembro de 2012 e 29 de abril de 2013, foram

A composição do GT de formulação do PLIP foi formada inicialmente por Altamiro Borges (Centro de Estudos da Mídia Alternativa Barão de Itararé), Bruno Marinoni (Coletivo Intervozes), João Brant (Intervozes/FNDC), Lidyane Ponciano (FNDC-MG), Luana Bonone (ANPG - Associação Nacional dos Pós-Graduandos), Márcio Patusco (Clube de Engenharia), Sandra Elena (CRP-SP), Theófilo Rodrigues (Barão de Itararé) e Veridiana Alimonti (Idec - Instituto Brasileiro de Defesa do Consumidor). Outros nomes somaram-se, posteriormente, ao GT, como os professores Marcos Dantas, Venício Lima, Edgard Rebouças e a jornalista Renata Mielli (Barão de Itararé/FNDC). 
muitos os debates internos no GT de formulação sobre quais deveriam ser as diretrizes centrais do PLIP. Finalmente, de modo simbólico, o "PLIP da mídia democrática" foi lançado no dia $1^{\circ}$ de maio de 2013, dia do trabalhador.

Ao longo de seus 33 artigos, o PLIP da Mídia Democrática traz um conjunto de diretrizes para a regulação da mídia no Brasil, com especial atenção para a regulamentação dos artigos da Constituição de 1988 que não foram efetivados. Entre os pontos principais que constam no documento, estão: (1) o fim da propriedade cruzada; (2) a regionalização da produção cultural; (3) o direito de antena para os movimentos sociais; (4) o direito de resposta.

0 fim da propriedade cruzada foi o mecanismo que os formuladores do PLIP encontraram para combater o monopólio e o oligopólio, conforme orienta 0 artigo 220 da Constituição. 0 capítulo 4 do PLIP, intitulado "Dos mecanismos para impedir a concentração, o monopólio ou oligopólio", é constituído por cinco artigos - do 14 ao 18. A base desses artigos é o limite na quantidade de concessões que uma mesma empresa pode ter. Esse limite é tanto vertical quanto horizontal: vertical na medida em que, como atesta 0 artigo 16, a mesma empresa não pode "obter outorga para explorar serviços de comunicação social eletrônica se já explorar outro serviço de comunicação social eletrônica na mesma localidade, se for empresa jornalística que publique jornal diário". Já a limitação horizontal está presente no artigo 14 quando afirma que "0 mesmo grupo econômico não poderá controlar diretamente mais do que cinco emissoras no território nacional". Cabe ressaltar que esse mecanismo de proibição da propriedade cruzada dos meios de comunicação não seria uma inovação brasileira, mas sim uma cópia do que já existe na legislação de grandes países em todo o mundo. De acordo com o indicado por João Brant:

Países como Estados Unidos, França e Reino Unido adotam esses limites por entenderem que a concentração de vozes afeta suas democracias. É importante notar que nesses países esses limites são antigos, mas têm sido revistos e, via de regra, mantidos - ainda que relaxados, em alguns casos. Mesmo com todos os processos liberalizantes, revisões regulares de seus marcos regulatórios e convergência tecnológica, esses países seguem mantendo enxergando a propriedade cruzada como um problema (BRANT, 2011).

A necessidade da regionalização da produção cultural, conforme orienta 0 artigo 221 da Constituição Federal, também está presente no PLIP. Como o PL da deputada federal do Rio de Janeiro Jandira Feghali (PCdoB) encontrou dificuldades de tramitação no Senado, 0 GT de formulação do PLIP considerou necessária sua inclusão. De acordo com os artigos 19 e 20 do PLIP, algumas cotas de participação da produção independente e regional devem ser obedecidas na grade de programação das emissoras.

Artigo 19 - Com vistas à promoção da diversidade regional, as emissoras de televisão terrestre deverão respeitar as seguintes exigências: I. As emissoras afiliadas a uma rede deverão 
ocupar no mínimo 30\% de sua grade veiculada entre $7 \mathrm{~h}$ e $0 \mathrm{~h}$ com produção cultural, artística e jornalística regional, sendo pelo menos sete horas por semana em horário nobre. II. As emissoras com outorgas locais devem ocupar no mínimo $70 \%$ de sua grade com produção regional.

Artigo 20 - As emissoras de televisão terrestre deverão veicular no horário nobre o mínimo de $10 \%$ de programação produzida por produtora brasileira independente, sendo no mínimo 50\% desse tipo de conteúdo realizado na própria área de mercado da emissora.

Ainda no que diz respeito ao conteúdo, o PLIP traz em seu artigo 21 o chamado Direito de antena para os movimentos sociais. Segundo esse artigo, as emissoras de televisão terrestre ou rádio deverão "assegurar, como direito de antena, 1 hora por semestre para cada um de 15 grupos sociais relevantes, definidos pelo órgão regulador por meio de edital com critérios transparentes e que estimulem a diversidade de manifestações". Isso significa que, assim como já ocorre com os partidos políticos, algumas organizações da sociedade civil passariam a ter o direito de uma determinada quantidade de propaganda gratuita nas concessões de rádio e televisão. A inspiração para esse direito de antena para os movimentos sociais vem da Constituição de Portugal, que criou essa possibilidade em 1976 logo após a Revolução dos Cravos ${ }^{3}$.

Por fim, um último ponto fundamental do PLIP é o que trata do direito de resposta. Esse direito encontra-se em um vácuo legislativo desde que o STF declarou, em 2009, inconstitucional a antiga Lei de Imprensa. Há no parlamento o projeto de lei 6446/2013, de autoria do senador Roberto Requião (PMDB-PR), o qual já chegou a ser aprovado no Senado, mas que ainda encontra resistências na Câmara dos Deputados na medida em que interfere diretamente nos interesses de poderosos lobbies do Congresso (BIANCHI, 2014, p. 92). Para solucionar esse problema, o PLIP propõe em seu artigo 250 seguinte texto sobre 0 direito de resposta:

Artigo 25 - 0 direito de resposta nos serviços de comunicação social eletrônica deve ser garantido de forma individual, coletiva ou difusa a todas as pessoas físicas ou jurídicas que forem acusadas ou ofendidas em sua honra ou a cujo respeito for veiculado fato inverídico ou errôneo em meios de comunicação. 0 espaço dado deve ser gratuito, igual ao utilizado para a acusação ou ofensa. 0 pedido de resposta deve ser atendido em até 48 horas após o recebimento da reclamação, após o que pode haver reclamação ao órgão regulador, que terá o poder de concedê-lo administrativamente.

0 PLIP era, portanto, uma clara sistematização dos pontos a serem regulamentados na Constituição de 1988 com algumas poucas inovações democráticas, caso do direito de antena. Produzido o PLIP, a tarefa da sociedade civil organizada em torno do FNDC passou a ser a seguinte a partir de $1^{\circ}$ de maio de 2013 : ocupar espaço na esfera pública, recolher as 
assinaturas necessárias para 0 encaminhamento para a Câmara dos Deputados, convencer os parlamentares e aprovar o projeto no Congresso. Esse é 0 tema da próxima seção.

\section{0 debate público}

Ao produzir o PLIP da mídia democrática, 0 conjunto das organizações da sociedade civil reunidas em torno do FNDC tinha o objetivo de levar para a esfera pública o debate sobre a necessidade de regulação da mídia no Brasil e, assim, influenciar positivamente 0 parlamento para a regulamentação dos artigos da Constituição que tratam da comunicação social. ${ }^{4}$ De fato, a ampla mobilização, seja pela mídia alternativa que assumiu a defesa do PLIP, seja pelas atividades de rua organizadas pelos movimentos sociais, trouxe esse debate para a agenda política. Um exemplo disso foi a ampla preocupação anunciada em editoriais dos dois maiores jornais impressos do país, O Globo e o Estadão. Vejamos.

Intitulado Há regulação da mídia e "regulação da mídia", 0 editorial de 0 Globo de 07 de abril de 2013 apresentou, de maneira nítida, a opinião do jornal sobre o tema, qual seja, a de que a proposta de regulação da mídia teria como consequência o fim da independência das empresas de comunicação.
A "regulação" do desejo dessa militância visa a interferir no conteúdo jornalístico - censura, a palavra certa. Como tem ocorrido na Venezuela, no Equador, nos países ditos bolivarianos, este objetivo é alcançado pela rota dissimulada da desestabilização empresarial dos grupos de comunicação. A Argentina é outro exemplo. Em nome da necessidade de se estimular a concorrência no mercado de imprensa e entretenimento - como se ela já não existisse no país força-se a quebra de conglomerados de comunicação, para que eles passem a depender de verbas públicas, o fim de sua independência ( 0 GLOBO, 07.04.2013).

0 editorial supramencionado de $O$ Globo acerta apenas em parte. É correto afirmar que a agenda política do FNDC, a qual alguns dias mais tarde seria materializada na forma do PLIP, passa pela "quebra de conglomerados de comunicação", embora a afirmação de que isso seja feito "para que eles passem a depender de verbas públicas" seja apenas uma ilação. Como vimos na seção anterior, essa "quebra de conglomerados de comunicação" seria a consequência do fim da propriedade cruzada que está proposto no PLIP. Contudo, a afirmação de que "a 'regulação' do desejo dessa militância visa a interferir no conteúdo jornalístico - censura, a palavra certa" é incorreta na medida em que 0 PLIP não trata em nenhum momento do conteúdo jornalístico. Com efeito, esse editorial de $O$ Globo ainda não conhecia o conteúdo do PLIP, que só veio a ser publicado alguns dias depois, em $1^{0}$ de maio de 
2013. Um novo editorial do jornal $O$ Globo foi

publicado em 10 de setembro de 2013. Dessa vez, já sendo conhecido o conteúdo do PLIP, o editorial intitulado 0 que significa democratização da mídia centrou sua argumentação no que seria a desnecessidade de haver uma regulação dos meios de comunicação. Em suas palavras,

Sequer falta regulação, porque os veículos estão subordinados a várias normas: Estatuto da Criança e do Adolescente (toda a imprensa), Lei da Classificação Indicativa (programação de TV), Agência Nacional de Telecomunicações (Anatel), etc. Resta provado que os melhores agentes do "controle social da mídia" são o leitor, o ouvinte, a autorregulamentação e o controle remoto. É assim que funciona nas democracias, ainda mais em mercados competitivos como 0 brasileiro (0 GLOBO, 07.09.2013).

O jornal Estado de São Paulo foi outro grande veículo da mídia impressa que destinou alguns editoriais para criticar a regulação da mídia. Um exemplo foi o editorial $O$ PT e a regulação da mídia, publicado em 18 de junho de 2014. Nele, o jornal ataca as razões pelas quais o PT tem defendido a regulação da mídia, confundindo o PT com o movimento da sociedade civil que propõe a democratização da mídia e que é muito mais amplo que apenas uma única legenda partidária. Curiosamente, ao contrário de $O$ Globo, o editorial do Estadão inicia reconhecendo a necessidade de haver uma regulamentação dos artigos da Constituição que tratam da comunicação social.

Por que, afinal, o Partido dos Trabalhadores (PT) tem verdadeira obsessão pela regulamentação da mídia? Por várias razões. Duas delas, justiça se faça, atendem a imperativos da modernização e aperfeiçoamento do arcabouço legal que regula os meios de comunicação. A primeira: 0 Capítulo V, artigos 220 a 224, da Constituição de 1988, que trata "Da comunicação social", permanece até hoje desregulamentado. A segunda: 0 Código Brasileiro de Telecomunicações, de 1962, que normatiza também o rádio e a televisão, é completamente obsoleto. Quando foi promulgado, há mais de meio século, nem a internet existia (ESTADÃO, 18.06.2014).

Todavia, o fato de reconhecer a necessidade da regulamentação da mídia não faz com que 0 Estadão deixe de criticar as iniciativas em curso. " 0 que de fato leva 0 partido a defender 0 que eufemisticamente chama de 'democratização da mídia' é a intenção de controlar os meios de comunicação para viabilizar seu projeto de manutenção no poder a qualquer custo", afirma o Estadão em seu editorial. Ou seja, mesmo reconhecendo a necessidade da regulação, o jornal a nega de forma casuística por acreditar que apenas beneficiará o PT. Essa linha, apresentada em 2014, é a mesma que o jornal já tinha em 2011. 0 editorial intitulado "Democratização", não controle, de 13 de outubro de 2011, indicava que o Estadão já reconhecia a necessidade de atualização do marco regulatório. No entanto, essa atualização não deveria ser confundida com controle do conteúdo.

Uma coisa é o problema da atualização do marco regulatório da comunicação eletrônica, necessária em razão da enorme defasagem da legislação vigente em relação aos avanços tecnológicos na área. Outra coisa é a tentativa de regulação - censura, em português claro - dos conteúdos veiculados por todas as mídias, inclusive a impressa (ESTADÃO, 13.10.2011). 
A diferença entre os editoriais dos dois grupos empresariais pode ter uma razão óbvia: a matriz de exploração comercial adotada por cada um deles. Ao Estado de São Paulo interessa a separação entre uma regulação da mídia impressa - que o jornal define como censura e, portanto, desnecessária - e uma regulação da mídia eletrônica - que considera necessária. Como o Estadão não explora concessões da comunicação social eletrônica - rádio e televisão -, não há uma preocupação em impedir tal regulação. Por outro lado, como o jornal $O$ Globo faz parte de um conglomerado econômico muito maior, o qual, inclusive, explora concessões de rádio e televisão, não há o interesse em apoiar nenhuma forma de regulação da mídia, seja impressa, seja eletrônica.

0 embate entre os defensores do PLIP e seus críticos ocorrido no âmbito da esfera pública alcançou rapidamente a sociedade política. 0 primeiro sinal veio em 2014 com as reiteradas declarações da então candidata à reeleição presidencial, Dilma Rousseff. Em pelo menos três importantes debates televisivos, Dilma anunciou que se vencesse a eleição, iniciaria aquilo que definiu como a "regulação econômica da mídia”, ou seja, a regulação da propriedade cruzada dos meios de comunicação. Mais do que isso, em coletiva concedida para alguns blogueiros da mídia alternativa no dia 26 de setembro de 2014, a presidenta declarou, com todas as palavras, o que compreendia como "regulação econômica da mídia":

Desde a Constituição de 1988, há um artigo, 0 220 , que diz que os meios sociais de comunicação não podem ser objeto de monopólio ou oligopólio. Em qualquer setor com concentração de propriedade, cabe a regulação. Primeiro, porque há uma assimetria imensa entre 0 detentor do monopólio e o resto das pessoas. E eu acredito que a base dessa regulação é a econômica. ${ }^{5}$

Em outras palavras, o reconhecimento de que 0 artigo 220 da Constituição precisava ser regulamentado atingiu o ponto mais alto da sociedade política, a Presidência da República. Entretanto, não foi apenas sob a chave positiva que o PLIP alcançou a sociedade política. Dois outros importantes nomes da República declararam-se contrários à ideia: 0 então presidente da Câmara dos Deputados, Eduardo Cunha (PMDB), e o presidente do Senado, Renan Calheiros (PMDB). Em entrevista ao jornalista Kennedy Alencar, em 11 de novembro de 2014, o então candidato à presidência da Câmara Eduardo Cunha deixou claro o que pensa sobre a regulação da mídia:

Regulação de mídia jamais. Eu colocaria na gaveta. Não faz parte do meu propósito. Eu sou muito claro, transparente para que todos saibam que eu, eleito presidente da Câmara, não darei curso a um projeto de regulação de mídia, afirmou 0 deputado. ${ }^{6}$ 
0 discurso é exatamente 0 mesmo do presidente do Senado, Renan Calheiros, o que indica ser essa uma tese consensual no PMDB. "Reitero que não apoio, não comungo, sequer admito discutir iniciativa, a qualquer pretexto, que pretenda regular a mídia", declarou Calheiros em 11 de junho de $2014 .^{7}$

Seja pela chave positiva, caso da então presidenta Dilma Rousseff, seja pela negativa, Cunha e Calheiros, é inegável o fato de que o tema da regulação da mídia proposto pelo PLIP do FNDC alcançou a esfera pública e a sociedade política após um movimento de baixo para cima, a partir da articulação e mobilização da sociedade civil e dos movimentos sociais. Tal resultado reforça a hipótese aqui apresentada, de que o Projeto Popular de Lei pode ser uma estratégia bemsucedida em trazer um tema para a cena política da agenda nacional.

\section{O obstáculo do Coronelismo eletrônico}

Apesar da apontada mobilização da sociedade civil em torno da democratização da comunicação, ainda se impõe à agenda o desafio de superar a relação viciada entre 0 controle da mídia e a composição das casas legislativas, esforço que deve envolver a eliminação do chamado coronelismo eletrônico.
De acordo com Venício Lima e Cristiano Lopes (2007), o coronelismo eletrônico é um fenômeno do Brasil urbano da segunda metade do século 20, que sofre uma inflexão importante com a Constituição de 1988, mas persiste e se reinventa depois dela. É também resultado da adoção do modelo de curadoria (trusteeship model), isto é, da outorga pela União a empresas privadas da exploração dos serviços públicos de rádio e televisão e, sobretudo, das profundas alterações que ocorreram com a progressiva centralidade da mídia na política brasileira, a partir do regime militar (1964-1985).

Emissoras de rádio e televisão, as quais são mantidas em boa parte pela publicidade oficial e estão articuladas com as redes nacionais dominantes, dão origem a um tipo de poder agora não mais coercitivo, mas criador de sensos comuns políticos, que facilitam (mas não garantem) a eleição (e a reeleição) de representantes - em nível federal, deputados e senadores - que, por sua vez, permitem, circularmente, a permanência do coronelismo como sistema. Ao controlar as concessões, o novo "coronel" promove a si mesmo e aos seus aliados, hostiliza e cerceia a expressão dos adversários políticos e é fator importante na construção da opinião pública, cujo apoio é disputado tanto no plano estadual como no federal. No coronelismo eletrônico, portanto, a moeda de troca continua 
sendo o voto, como no velho coronelismo, só que não mais com base na posse da terra, mas no controle da informação - vale dizer, na capacidade de influir na formação da opinião pública. A recompensa da União aos coronéis eletrônicos é, de certa forma, antecipada pela outorga e, depois, pela renovação das concessões do serviço de radiodifusão que confere a eles poder na barganha dos recursos para os serviços públicos municipais, estaduais e federais.

Por esse mecanismo, conforme pesquisa de Suzy Santos e Sérgio Capparelli (2005), quem acaba ocupando cargos políticos - especialmente no Poder Legislativo, onde se poderia aprovar a regulamentação da comunicação social - são, em grande parte, agentes comprometidos com as oligarquias que controlam os meios de comunicação no país, obstaculizando a entrada da pauta dos movimentos sociais nos grandes meios de comunicação. Desse modo, sem alcançar a massificação do debate, a sociedade civil organizada parece não ter chances de convencer 0 restante da sociedade brasileira da necessidade da regulação da mídia.

0 grande desafio do movimento de democratização da mídia, portanto, é encontrar e ocupar as fissuras nesse jogo de poder quase retroalimentar entre parlamento e oligarquia midiática, a fim de produzir massa crítica em larga escala, que reflita a necessidade de regulação no âmbito do poder legislativo.

\section{Considerações finais}

Ao longo deste artigo, procuramos demonstrar como a inércia e/ou omissão legislativa no que tange à regulamentação dos meios de comunicação levou uma grande quantidade de organizações da sociedade civil reunidas em torno do FNDC a buscarem uma forma alternativa de pressão social sobre o parlamento: a formulação de um projeto de lei de iniciativa popular. A mobilização social em torno desse PLIP encontrou nos editoriais dos dois maiores veículos da mídia impressa brasileira seus maiores adversários no âmbito da esfera pública. Partindo da sociedade civil, essa agenda conseguiu alcançar a sociedade política, a ponto de os três maiores nomes da República brasileira terem adotado posicionamentos em relação ao tema.

Nesse sentido, 0 artigo testou a hipótese de que, ao analisar o conteúdo do projeto de lei de iniciativa popular, foi possível destacar como foram as estratégias adotadas de propostas de regulação pela sociedade civil para levá-lo ao Congresso Nacional. Buscou-se reforçar que a iniciativa popular de lei constituiu uma estratégia acertada no tema da regulação da mídia, se considerada a proposta de tornar a questão como pauta da agenda nacional de democratização. Dentre outros resultados apresentados, deve-se ressaltar também o fato de que essa tradição em torno da mobilização social sobre emendas populares remonta ao momento constituinte de 1988. 
Ao tratar das táticas e estratégias organizativas em torno da proposta de emenda popular de lei, também foram postos em evidência alguns dos elementos que tornam o marco legal das comunicações ainda insuficiente.

Um dos argumentos adotados pelos críticos da regulação da mídia foi, como vimos, o de que seria uma forma de censura. Contudo, a literatura especializada já demonstrou que os dois termos - regulação e censura - não devem ser confundidos. Nas palavras de um experiente especialista sobre 0 tema,

Pode-se justificar o discurso de confusão entre censura e regulação de conteúdo, habitualmente ecoado pelos meios de comunicação de massa, por meio das condicionantes históricas nacionais. Diante do autoritarismo marcante de distintos regimes e governos nas últimas décadas e do avanço proporcionado pela Constituição Federal de 1988, poderia ser um retrocesso a aceitação de medidas restritivas. Esse discurso, no entanto, revela-se imobilizador e compatível com um entendimento limitado da liberdade de expressão. Ao rechaçar qualquer proposição de regulação de conteúdo, opõe-se, em termos de princípios, à regulamentação da própria Carta Magna, o que ainda não foi feito em grande parte do capítulo constitucional referente à comunicação social (PIERANTI, 2008, p. 141).

Outro argumento utilizado pelas empresas de comunicação contrárias ao PLIP é o de que essa regulação seria apenas utilizada por países autoritários, ou, como preferem, "bolivarianos". Informação inverídica se constatarmos, após uma observação comparada, que a maior parte dos países democráticos do mundo adotou algum mecanismo de regulação sobre suas empresas de comunicação. É o que atesta, por exemplo, o jornalista Franklin Martins, ex-ministro da Secretaria de Comunicação Social do governo Lula:

Praticamente todas as sociedades democráticas do mundo consideram imprescindível algum tipo de regulação dos meios de comunicação, notadamente daqueles que, como 0 rádio e a televisão, são objetos de concessão do Estado. Em alguns países, como nos Estados Unidos, a regulação é principalmente econômica, por meio da proibição da chamada propriedade cruzada. Ou seja, grupos de comunicação não podem possuir simultaneamente emissoras de televisão, estações de rádio e jornais numa mesma cidade ou estado (MARTINS, 2014, p. 8).

Independentemente do mérito da proposta, fato é que a estratégia adotada pelas organizações da sociedade civil de apropriação do PLIP como instrumento de mobilização social e de agendamento de políticas públicas parece ter sido acertada. Embora ainda não tenha sido vitorioso, ou seja, não tenha conseguido as assinaturas necessárias, o PLIP passou a fazer parte da narrativa da então própria presidenta da República, o que não é, seguramente, pouca coisa. Contudo, para que a mobilização da sociedade civil continue avançando até a aprovação do PLIP, é necessário que o movimento social logre expandir a consciência da sociedade civil brasileira em geral sobre 0 tema, superando o desafio que consiste na problemática da retroalimentação entre formação de opinião pública e maciça ocupação de cargos públicos no parlamento pelos mesmos agentes: os donos da mídia e seus representantes. 


\section{Referências}

BACHRACH, Peter; BARATZ, Morton S.. Duas faces do poder. Revista Sociologia Política, Curitiba, v. 19, $\mathrm{n}^{0}$ 40, out. 2011.

BIANCHI, Felipe. Direito de resposta evitaria crimes da mídia. In: MIELLI, Renata (Org.). Direitos negados: um retrato da luta pela democratização da comunicação. São Paulo: Barão de Itararé, 2015.

BRANT, João. Por que e como se limita a propriedade cruzada. Disponível em: http://www. direitoacomunicacao.org.br/content.php?option $=$ com content\&task $=$ view\&id $=7514$. Último acesso em dezembro de 2012.

\section{BRASIL. Constituição da República Federativa do}

Brasil. Disponível em: < http://www.planalto.gov.br/ ccivil_03/constituicao/constituicao.htm > .1988. Acesso em: dez. 2014

ESTADÃO. 0 PT e a regulação da mídia. 18 de junho de 2014.

"Democratização", não controle. 13

de outubro de 2011.

FARIA, Alessandra Maia Terra de. Participação e representação: as políticas públicas de saúde no Rio de Janeiro. Tese de doutoramento, Rio de Janeiro: Departamento de Ciências Sociais, Pontifícia Universidade Católica do Rio de Janeiro (PUC-Rio), 2014.

LIMA, Venício A. de., LOPES, Cristiano Aguiar. Coronelismo eletrônico de novo tipo (1999-2004).

PR0J0R, 2007. Disponível em: http://www. observatoriodaimprensa.com.br/download/Coronelismo eletronico_de_novo_tipo.pdf. Acesso em: 17 out. 2015.

MARTINS, Franklin. Prefácio. In: LIMA, Venício. Para garantir o direito à comunicação. São Paulo: Barão de Itararé, 2014.

MIELLI, Renata (Org). Direitos negados: um retrato da luta pela democratização da comunicação. São Paulo: Barão de Itararé, 2015.
0 GLOBO. Há regulação da mídia e "regulação da mídia". 07 de abril de 2013. . 0 que significa democratização da mídia. 07 de setembro de 2013.

PIERANTI, Octavio Penna. Censura versus regulação de conteúdo: em busca de uma definição conceitual. In: (Orgs.) SARAVIA, Enrique; MARTINS, Paulo Emilio; PIERANTI, Octavio Penna. Democracia e regulação dos meios de comunicação de massa. Rio de Janeiro: Editora FGV, 2008.

RODRIGUES, Theófilo. A Constituição de 1988 e a comunicação: história de um processo inacabado de regulamentação. Revista Mosaico, $n^{0}$ 7, ano IV, 08 de janeiro de 2014.

SANTOS, Suzy CAPPARELLI, Sérgio. "Coronelismo, radiodifusão e voto: a nova face de um velho conceito". In: BRITTOS, Valério Cruz BOLAÑO, César Ricardo Siqueira (Org.) Rede Globo: 40 anos de poder e hegemonia. $1^{\mathrm{a}}$ ed. São Paulo: Paulus, 2005, v.1, p. 77101. 


\begin{tabular}{|c|c|}
\hline $\begin{array}{l}\text { Civil society and } \\
\text { media regulation: } \\
\text { a case study on equity } \\
\text { of democratic media }\end{array}$ & $\begin{array}{l}\text { La sociedad civil y la regulación } \\
\text { de los medios: un estudio de caso } \\
\text { sobre el patrimonio de los medios } \\
\text { de comunicación democrática }\end{array}$ \\
\hline $\begin{array}{l}\text { Abstract } \\
\text { The purpose of this paper is to present the way in } \\
\text { which a portion of the Brazilian civil society has } \\
\text { brought to the field of public sphere the debate } \\
\text { about the regulation of constitutional articles } \\
\text { dealing with the media. We selected a case study } \\
\text { the recent social mobilization around the popular } \\
\text { initiative bill of democratic media. At first we will } \\
\text { discuss the constitutional articles related to the } \\
\text { topic of the media and the way in which they gave } \\
\text { their regulation or non-regulation over the past } 27 \\
\text { years. By analyzing these processes will be tested } \\
\text { the hypothesis that guides this article, namely, that } \\
\text { a popular initiative bill could prove a successful } \\
\text { strategy for civil society in making certain topic, } \\
\text { in this case - the media, agenda of the national } \\
\text { democratic agenda. } \\
\text { Keywords } \\
\text { Media regulation. Civil society. Public sphere. }\end{array}$ & $\begin{array}{l}\text { Resumen } \\
\text { El propósito de este trabajo es presentar la manera } \\
\text { en que una parte de la sociedad civil brasileña ha } \\
\text { traído al campo de debate en la esfera pública acerca } \\
\text { de la regulación de los artículos constitucionales } \\
\text { relativos a los medios de comunicación. Por que fue } \\
\text { recortada, como un estudio de caso de la reciente } \\
\text { movilización social en torno del proyecto de ley de } \\
\text { iniciativa popular de los medios de comunicación } \\
\text { democrática. Al principio se discutirán los artículos } \\
\text { constitucionales relacionados con el tema de los } \\
\text { medios de comunicación y la forma en la que dieron } \\
\text { su regulación o no regulación en los últimos } 27 \text { años. } \\
\text { Mediante el análisis de estos procesos se pondrá a } \\
\text { prueba la hipótesis que guía este artículo, a saber, } \\
\text { que un proyecto de ley de iniciativa popular podría } \\
\text { ser una estrategia exitosa para la sociedad civil en } \\
\text { la toma de determinado tema, en este caso - los } \\
\text { medios de comunicación, orden del día de la agenda } \\
\text { democrática nacional. } \\
\text { Palabras clave } \\
\text { Regulación de los medios. Sociedad civil. } \\
\text { Esfera pública. }\end{array}$ \\
\hline
\end{tabular}




\section{Expediente}

A revista E-Compós é a publicação científica em formato eletrônico da Associação Nacional dos Programas de Pós-Graduação em Comunicação (Compós). Lançada em 2004, tem como principal finalidade difundir a produção acadêmica de pesquisadores da área de Comunicação, inseridos em instituições do Brasil e do exterior.

\section{E-COMPÓS I www.e-compos.org.br I E-ISSN 1808-2599}

Revista da Associação Nacional dos Programas de Pós-Graduação em Comunicação. Brasília, v.19, n.2, maio/ago. 2016. A identificação das edições, a partir de 2008, passa a ser volume anual com três números. Indexada por Latindex I www.latindex.unam.mx

\section{CONSELHO EDITORIAL}

\section{Alexandre Farbiarz, Universidade Federal Fluminense, Brasi}

Alexandre Rocha da Silva, Universidade Federal do Rio Grande do Sul, Brasil Ana Carolina Escosteguy, Pontifícia Universidade Católica do Rio Grande do Sul, Brasil Ana Carolina Rocha Pessôa Temer, Universidade Federal de Goiás, Brasil Ana Regina Barros Rego Leal, Universidade Federal do Piauí, Brasil Andrea França, Pontifícia Universidade Católica do Rio de Janeiro, Brasil André Luiz Martins Lemos, Universidade Federal da Bahia, Brasil Antonio Carlos Hohlfeldt, Pontifícia Universidade Católica do Rio Grande do Sul, Brasil Arthur Ituassu, Pontifícia Universidade Católica do Rio de Janeiro, Brasil Álvaro Larangeira, Universidade Tuiuti do Paraná, Brasil

Ângela Freire Prysthon, Universidade Federal de Pernambuco, Brasil César Geraldo Guimarães, Universidade Federal de Minas Gerais, Brasil Cláudio Novaes Pinto Coelho, Faculdade Cásper Líbero, Brasil Daisi Irmgard Vogel, Universidade Federal de Santa Catarina, Brasil Denize Correa Araujo, Universidade Tuiuti do Paraná, Brasil Eduardo Antonio de Jesus, Pontifícia Universidade Católica de Minas Gerais, Brasil Daniela Zanetti, Universidade Federal do Espírito Santo, Brasil Eduardo Vicente, Universidade de São Paulo, Brasil

Elizabeth Moraes Gonçalves, Universidade Metodista de São Paulo, Brasil Erick Felinto de Oliveira, Universidade do Estado do Rio de Janeiro, Brasil Francisco Elinaldo Teixeira, Universidade Estadual de Campinas, Brasil Francisco Paulo Jamil Almeida Marques, Universidade Federal do Paraná, Brasil Gabriela Reinaldo, Universidade Federal do Ceará, Brasil

Goiamérico Felício Carneiro Santos, Universidade Federal de Goiás, Brasil Gustavo Daudt Fischer, Universidade do Vale do Rio dos Sinos, Brasil Herom Vargas, Universidade Municipal de São Caetano do Sul, Brasil Itania Maria Mota Gomes, Universidade Federal da Bahia, Brasil Janice Caiafa, Universidade Federal do Rio de Janeiro, Brasil Jiani Adriana Bonin, Universidade do Vale do Rio dos Sinos, Brasil
José Afonso da Silva Junior, Universidade Federal de Pernambuco, Brasil José Luiz Aidar Prado, Pontifícia Universidade Católica de São Paulo, Brasil Juçara Gorski Brittes, Universidade Federal de Ouro Preto, Brasil Kati Caetano, Universidade Tuiuti do Paraná, Brasil Lilian Cristina Monteiro França, Universidade Federal de Sergipe, Brasil Liziane Soares Guazina, Universidade de Brasilia, Brasil Luíza Mônica Assis da Silva, Universidade de Caxias do Sul, Brasil Luciana Miranda Costa, Universidade Federal do Pará, Brasil Malena Segura Contrera, Universidade Paulista, Brasil Monica Martinez, Universidade de Sorocaba, Brasil Maria Ataide Malcher, Universidade Federal do Pará, Brasil Marcia Tondato, Escola Superior de Propaganda e Marketing, Brasil Marcel Vieira Barreto Silva, Universidade Federal da Paraiba, Brasil Maria Clotilde Perez Rodrigues, Universidade de São Paulo, Brasil Maria das Graças Pinto Coelho, Universidade Federal do Rio Grande do Norte, Brasil Mauricio Ribeiro da Silva, Universidade Paulista, Brasil

Mauro de Souza Ventura, Universidade Estadual Paulista, Brasil Márcio Souza Gonçalves, Universidade do Estado do Rio de Janeiro, Brasil Micael Maiolino Herschmann, Universidade Federal do Rio de Janeiro, Brasil Mirna Feitoza Pereira, Universidade Federal do Amazonas, Brasil Nísia Martins Rosario, Universidade Federal do Rio Grande do Sul, Brasil Potiguara Mendes Silveira Jr, Universidade Federal de Juiz de Fora, Brasil Regiane Regina Ribeiro, Universidade Federal do Paraná, Brasil Rogério Ferraraz, Universidade Anhembi Morumbi, Brasil Rose Melo Rocha, Escola Superior de Propaganda e Marketing, Brasil Rozinaldo Antonio Miani, Universidade Estadual de Londrina, Brasil Sérgio Luiz Gadini, Universidade Estadual de Ponta Grossa, Brasil Simone Maria Andrade Pereira de Sá, Universidade Federal Fluminense, Brasil Veneza Mayora Ronsini, Universidade Federal de Santa Maria, Brasil Walmir Albuquerque Barbosa, Universidade Federal do Amazonas, Brasil
COMISSÃO EDITORIAL Eduardo Antonio de Jesus, Pontifícia Universidade Católica de Minas Gerais, Brasil I Osmar Gonçalves dos Reis Filho, Universidade Federal do Ceará, Brasi

CONSULTORES AD HOC Alexandre Almeida Barbalho, Universidade Estadual do Ceará, Brasil | Alexandre Rocha da Silva, Universidade Federal do Rio Grande do Sul, Brasil | Bruno Souza Leal, Universidade Federal de Minas Gerais, Brasil I Carlos Eduardo Franciscato, Universidade Federal do Sergipe, Brasil I Eneus T. Barreto Filho, Universidade de São Paulo, Brasil I Felipe da Costa Trotta, Universidade Federal Fluminense, Brasi | Henrique Codato, Universidade Federal do Ceará, Brasil I Ines S. Vitorino Sampaio Universidade Federal do Ceará, Brasil I Jairo Getulio Ferreira, Universidade do Vale do Rio dos Sinos, Brasil I Juliana Freire Gutmann, Universidade Federal da Bahia, Brasil | Júlio César M. Pinto, Pontifícia Universidade Católica de Minas Gerais, Brasil I Lucrecia D. Ferrara, Pontifícia Universidade Católica de São Paulo, Brasil I Marcio V. Serelle, Pontifícia Universidade Católica de Minas Gerais, Brasil I Maria Ignes C. Magno, Universidade Anhemb Morumbi, Brasil I Maria Lilia Dias de Castro, Universidade Federal de Santa Maria, Brasil | Mozahir S. Bruck, Pontifícia Universidade Católica de Minas Gerais, Brasil I Potiguara M. da Silveira Junior, Universidade Federal de Juiz de Fora, Brasil I Sandra Maria L. P. Gonçalves, Universidade Federal do Rio Grande do Sul, Brasil I Suzana Kilpp, Universidade do Vale do Rio dos Sinos, Brasil I Tiago Q. Fausto Neto, Universidade de Brasília, Brasil I Vera Regina V. Franca, Universidade Federal de Minas Gerais, Brasil I Virginia P. S. Fonseca, Universidade Federal do Rio Grande do Sul, Brasil

EQUIPE TÉCNICA ASSISTENTE EDITORIAL Márcio Zanetti Negrini REVISÃo DE TEXTOS Press Revisão I EDITORAÇÃO ELETRÔNICA Roka Estúdio

\section{COMPÓS I www.compos.org.br}

Associação Nacional dos Programas de Pós-Graduação em Comunicação

Presidente

Edson Fernando Dalmonte

Programa de Pós-Graduação em Comunicação

e Cultura Contemporânea - UFBA

edsondalmonte@uol.com.br

Vice-presidente

Cristiane Freitas Gutfreind

Programa de Pós-Graduação em Comunicação Social - PUC-RS cristianefreitas@pucrs.br

Secretário-Geral

Rogério Ferraraz

Programa de Pós-Graduação em Comunicação

Universidade Anhembi Morumbi

rogerioferraraz@anhembimorumbi.edu.br

CONTATO I revistaecompos@gmail.com 